\section{The effects of imagery on the paired-associate learning of adjectives*}

\author{
KENNETH A. JACOBUS, University of Kentucky, Lexington, Ky. 40506 \\ S. DAVID LEONARD, University of Georgia, Athens, Ga. 30601 \\ and \\ R. PAUL STRATTON, University of Kentucky, Lexington, Ky. 40506
}

Imagery (I) of adjectives was varied on the stimulus and response sides of paired-associate tasks in both mixed-list (ML) and unmixed-list (UL) paradigms. In the ML paradigm, high-I response terms were learned significantly better than low-I response terms. More correct responses were given to high-I stimuli in the ML paradigm than to low-I stimuli, although reliability was statistically demonstrated only for the first five trials. No significant effects of I were found in the UL paradigm. These results were compared with those obtained in research with the I variable using nouns.

A number of recent studies have provided evidence in support of the effectiveness of word imagery (I) as a variable relevant to various learning tasks (cf. Paivio, 1969). These studies have varied I among words which are classed primarily as nouns. The present report describes two experiments performed in an attempt to extend the findings regarding the effects of $I$ to words of a different form class adjectives.

The task selected was a paired-associate (PA) learning task. The effects of I on both the stimulus and the response members of $P A$ pairs was studied. Both unmixed-list (UL) and mixed-list (ML) paradigms were used.

In addition to the use of adjectives, the experiments were designed to control for the effects of the variable distinctiveness (D) which had not been controlled in previous experiments. However, since some studies have shown $D$ to be a factor in stimulus selection (Jacobus \& Leonard, 1968; Leonard \& Jacobus, 1969) in PA learning, it was decided to include this control. Additional controls were imposed on the level of meaningfulness $(m)$ and on the level of frequency of usage (u). The latter variable was used in preference to a frequency of occurrence measure such as the Thorndike-Lorge (1944) word count because its scale properties included a definitive range and specific values for each word.

METHOD

\section{Experiment 1}

Materials. The words for this experiment were 32 adjectives selected from a list of 150 two-syllable adjectives which are used primarily as adjectives for which values of $I, D, m$, and $u$ had been obtained. The I values

*The study was supported in part by a grant from the University of Kentucky Research Foundation. were obtained by a rating procedure closely following that of Paivio, Yuille, \& Madigan (1968), with the modification that a 5 -point scale was used in contrast to the 7 -point scale used by Paivio et al. The $D$ values were obtained from the results of a short-term recognition memory experiment similar to that performed by Shepard \& Teghtsoonian (1961) The $D$ values were defined in terms of the number of hits (words correctly identified as "old") minus the number of false alarms ("new" words incorrectly identified as "old") made by a number of $S s$ on the task. The $m$ values were obtained essentially by Noble's (1952) production technique. The $u$ values were based on subjective ratings on a 5 -point scale.

Four PA lists were constructed by randomly pairing eight adjectives as stimuli with the digits $2-9$ as responses. The words for two of the lists (the $\mathrm{H}_{1}$ and $\mathrm{H}_{2}$ words) were high in $\mathrm{I}$, while the words for the other two lists (the $\mathrm{L}_{1}$ and $\mathrm{L}_{2}$ words) were low in I. These four groups of words are presented in Table 1 . The mean values and the range of individual values on the $I$ dimension were $4.38(3.92-4.56)$ and $4.31(4.04-4.48)$ for the $\mathrm{H}_{1}$ and $\mathrm{H}_{2}$ words, respectively, while the means and ranges for the $L_{1}$ and $L_{2}$ words were $2.69(2.30-2.98)$ and 2.71 (2.48-2.84), respectively. The four groups of words were approximately equivalent in terms of their mean $D$, $m$, and $u$ values.
Four additional PA lists were constructed by reversing ("turning over") the stimulus-response positions of the four adjective-digit lists. Thus, the "turned-over" lists contained single digits as stimuli and adjectives as responses, one list containing $H_{1}$ words as responses, one containing $\mathrm{H}_{2}$ words as responses, and so forth.

Procedure. The pairs used in each PA list were arranged in six random orders and presented to Ss for a total of 12 trials ( 1 study and 11 anticipation trials) at a $2: 2-\mathrm{sec}$ rate with a 2 -sec intertrial interval on a standard memory drum.

Subjects. The Ss were introductory psychology students who were fulfilling a course requirement by participating in the experiment. Each $S$ was assigned to a list in order of appearance at the laboratory. Each list was presented to $10 \mathrm{Ss}$

Experiment 2

All materials and procedures were the same as those in Experiment 1, with the exception that within each PA list, four of the adjectives were high in I and four were low in I.

\section{RESULTS}

Preliminary analyses were performed in each experiment to determine whether or not there were reliable differences in number of correct responses attributable to the different lists within I level on the stimulus and response sides. Since no differences were found, the correct response data from the different lists were pooled in the analyses described below.

The analyses performed in the UL paradigm (Experiment 1) for all 11 anticipation trials involved $I$ levels and position (adjective-digit vs digit-adjective pairs) as between-S effects and trials as a within-S effect. Additional analyses performed on the first five anticipation trials involved only the I and position variables. In the ML (Experiment 2) analyses for the 11 anticipation trials, position was a between-S effect, while I and trials were within-S effects. Additional analyses performed on the first five anticipation trials involved only the I and position variables.

The mean number of correct responses for the high-I and low-I lists for both experiments are presented in

Table 1

High I and Low I Words

\begin{tabular}{llll}
\hline Group H1 & Group H2 & Group L1 & Group L2 \\
\hline Fertile & Rounded & Petty & Lofty \\
Vacant & Alive & Splendid & Vital \\
Massive & Spacious & Lawful & Zealous \\
Bitter & Childish & Certain & Drastic \\
Hairy & Gaudy & Exact & Partial \\
Lively & Homely & Immune & Valid \\
Naughty & Rigid & Needless & Ample \\
Ancient & Vicious & Adrift & Civil \\
\hline
\end{tabular}


Table 2

Means and Standard Deviations of the Number of Correct Responses as a Function of I Levels in Each Experiment

\begin{tabular}{|c|c|c|c|c|}
\hline \multirow[b]{2}{*}{ I Level/Trials } & \multicolumn{2}{|c|}{ Experiment 1} & \multicolumn{2}{|c|}{ Experiment 2} \\
\hline & Stimulus I & Response I & Stimulus I & Response I \\
\hline $\begin{array}{l}5 \text { Trials } \\
11 \text { Trials }\end{array}$ & $\begin{array}{c}18.55 \\
(8.91) \\
50.15 \\
(19.56)\end{array}$ & $\begin{array}{c}14.10 \\
(6.30) \\
50.70 \\
(13.11)\end{array}$ & $\begin{array}{c}10.45 \\
(4.83) \\
29.17 \\
(9.52)\end{array}$ & $\begin{array}{l}7.77 \\
(4.18) \\
25.37 \\
(8.86)\end{array}$ \\
\hline $\begin{array}{l}5 \text { Trials } \\
11 \text { Trials }\end{array}$ & $\begin{array}{c}15.80 \\
(7.37) \\
\mathbf{4 8 . 4 5} \\
(\mathbf{1 7 . 7 9 )}\end{array}$ & $\begin{array}{c}14.00 \\
(8.05) \\
47.15 \\
(17.85)\end{array}$ & $\begin{array}{l}9.07 \\
(4.28) \\
27.07 \\
(8.97)\end{array}$ & $\begin{array}{l}5.95 \\
(3.72) \\
21.80 \\
(9.70)\end{array}$ \\
\hline
\end{tabular}

Table 2. These results are presented in terms of the 11 anticipation trials and also the first 5 anticipation trials.

\section{Experiment 1}

In the analysis based on all 11 trials for the UL data, the effects of trials and Position by Trials were significant, with $\mathrm{Fs}(10,760)=128.35$ and 6.40 , respectively, ps $<.05$. All other effects produced Fs less than 1.00. The Position by Trial interaction was produced by faster learning of the pairs when I was varied on the stimulus side in the first few trials. This no doubt reflected response availability.

Since other studies (cf. Paivio \& Madigan, 1970) had indicated that the effects of varying I might occur in the early learning trials, an analysis involving I and position was performed on the data from the first five trials. The main effect of $I$ and the $I$ by Position interaction were not significant, $F \mathrm{~s}(1,78)<1.00$, ps $>.05$. Experiment 2

The effects of trials and Position by Trials were also significant for the ML data, $\operatorname{Fs}(10,780)=146.64$ and 2.29 , respectively, ps $<.05$. Again, the Position by Trials interaction was produced by faster learning of the pairs when I was varied on the stimulus side in the first few trials. The overall effect of position showed that significantly more correct responses were given when the adjectives were used as stimuli, $\mathrm{F}(1,78)=5.68$, $p<.05$.

In this paradigm, the main effect of I was significant, $F(1,78)=10.41$, $\mathrm{p}<.05$, but none of the interactions involving I were significant, all Fs $<1.00$. Since some studies (e.g. Yarmey \& Paivio, 1965) have found effects of $I$ on the stimulus side but not on the response side, it was decided to test these separately. The effect of $I$ on the response side was significant, $\quad F(1,39)=8.33, \mathrm{p}<.01$. However, the effect of I on the stimulus side was not statistically reliable, $F(1,9)=2.83, p>.10$.

An analysis involving $I$ and position was also performed on the five anticipation trials. As was the case for the analysis of the data for all 11 trials, the main effect of I was significant, $F(1,78)=12.80, p<.05$. Although the I by Position interaction was not significant, $F(1,78)<1.00$, $p>.10$, the effects of Stimulus $I$ and Response I were again tested separately. In this case, both Stimulus I and Response I showed significant effects, $F(1,39)=4.12$ and 8.20 , respectively, $\mathrm{p}<.05$.

\section{DISCÚSSION}

The results for the unmixed experiment were not in accord with results obtained with nouns (Yuille \& Paivio, 1968). Specifically, Yuille and Paivio found reliable effects of stimulus $I$ and response $I$, with the effects of stimulus I being greater than the effects of response I. The results of the present unmixed experiment indicated that none of the effects involving I were significant.

The results for the mixed experiment were more in accord with those obtained with nouns (e.g., Paivio \& Madigan, 1970). As in the noun studies, stimulus I and response I produced reliable effects. However, while in the case of nouns the stimulus I effects are greater than the response I effects, in the present mixed experiment, the stimulus I effects tended to be less than the response I effects.

These results suggest that the effects of I on the learning of adjectives may be somewhat different from the effects for nouns. However, caution should be used in drawing any conclusions from these results, since the present study differed from the noun studies in several other respects. First, the present study used the anticipation technique, while the study-recall technique has typically been used in the noun studies. The use of this latter technique might promote the formation of images more than does the anticipation technique. However, Yarmey \& Paivio (1965) used the anticipation technique with the UL paradigm and found a reliable effect of stimulus I. A second factor which might have affected the results of the present study was the use of digits as the other member of the S-R pair. Typically, noun studies have used words or trigrams in the other position. However, Dominowski \& Gadlin (1968) used digits as responses with the UL paradigm and found significant effects of imagery. Thus, it seems unlikely that these procedural differences were entirely responsible for the failure to obtain the significant effects obtained with nouns. However, the use of highly available response items may have contributed to the differential results found for stimulus vs response effects.

Other factors in the present experiments which differed from those previously cited were the control of $D$ and the use of a different measure of frequency. It is possible that either or both of these could have contributed to a lessening of the effect of I. There are not at present any data which bear on these effects.

A final possibility which might be relevant in this situation is that the absolute dispersion of I for adjectives may be smaller than the absolute dispersion of I for nouns. Since the norms obtained for adjectives were based only on ratings of adjectives, it is impossible to provide an adequate comparison of the dispersions for the two form classes. Research currently in progress may provide an answer to that question.

In summation, present results suggest that imagery may operate differently in the learning of adjectives than it does in the learning of nouns.

\section{REFERENCES}

DOMINOWSKI, R., \& GADLIN, H. Imagery and paired-associate learning. Canadian Journal of Psychology, 1968, 22, 336-348.

JACOBUS, K. A., \& LEONARD, S. D. The influence of distinctiveness on stimulus selection. Psychonomic Science, 1968. $13,339-340$.

LEONARD, S. D., \& JACOBUS, K. A. Locus of the effect of distinctiveness on response recall. Psychonomic Science, $1969,14,284-285$.

NOBLE, C. E。 An analysis of meaning. Psychological Review, 1952, 59, 421-430.

PAIVIO, A. Mental imagery in associative learning and memory. Psychological Review, 1969, 76, 241-263.

PAIVIO, A., \& MADIGAN, S. Noun imagery and frequency in paired-associate and free-recall learning. Canadian Journal of Experimental Psychology, 1970, 24, 35 3-361.

PAIVIO, A.. YUILLE, J., \& MADIGAN, S. Concreteness, imagery and meaningfulness values for 925 nouns. Journal of Experimental Psychology, 1968, 76, (1, Part 2), 1-25.

SHEPARD, R. N.. \& TEGHTSOONIAN, M. Retention of information under conditions approaching a steady state. Journal of Experimental Psychology, $1961,62,302-309$

THORNDIKE, E. L., \& LORGE, I. The teacher's word book of 30,000 words. New York: Bureau of Publications. 
Teachers College, Columbia University. 1944.

YARMEY * H., \& PAIVIO, A. Furthex evidence on the effects of word abstractness and meaningfulness in pairedissociate leaming. Psychonomic

Science, 1965, 2, 307-308. YUILLE, J., \& PAIVIO, A. Imagery and verbal mediation instructions in paired-associate leaming. Journal of Experimental Psychology, 1968, 78. 436-441. 